Gut, 1971, 12, 825-829

\title{
The fate of pentagastrin
}

\author{
BRIAN H. STAGG, JOHN M. TEMPERLEY, ${ }^{1}$ AND JOHN H. WYLLIE ${ }^{2}$ \\ From the Departments of Biochemical Pathology and Surgery, University College Hospital Medical School, \\ London
}

SUMMARY Pentagastrin is rapidly removed from the circulation of the dog. It is excreted by the liver into the bile, largely in an inactivated form. Preliminary results indicate that it meets the same fate in man.

The synthetic pentapeptide pentagastrin has the same biological effects as gastrin and is widely used to stimulate gastric acid secretion in tests in man and in animals. The fate of gastrin in the body is not precisely known: Clendinnen, Davidson, Lemmi, Jackson, and Thompson (1970) have suggested that it is inactivated on passage through the kidney and we have recently shown it to be inactivated as it traverses the small bowel vascular bed. In contrast, pentagastrin is unaffected by the small bowel, but loses potency as it passes through the liver (Temperley, Stagg, and Wyllie, 1971). In the present study the fate of pentagastrin in the liver has been investigated by experiments in anaesthetized dogs; pentagastrin is excreted into the bile, mainly in an inactive form.

\section{Methods}

PREPARATION OF DOGS

Twelve adult mongrel dogs of either sex weighing 9.3-16.8 $\mathrm{kg}$ (mean 13.1 kg) were anaesthetized by intravenous injection of pentobarbitone $(25 \mathrm{mg} / \mathrm{kg}$ body weight). Anaesthesia was maintained by further hourly injections of $5 \mathrm{mg} / \mathrm{kg}$. The trachea was intubated with a cuffed tube and the lungs were ventilated with air using a stroke volume of $20 \mathrm{ml} /$ $\mathrm{kg}$ body weight and a frequency of $25 /$ minute.

A polythene cannula was tied into the left external jugular vein; through it infusions of pentagastrin were given at a rate of $30 \mu \mathrm{g} / \mathrm{kg} / \mathrm{hr}(15 \mu \mathrm{g} / \mathrm{kg} / \mathrm{hr}$ in one experiment) by means of a Watson Marlow MHRE delta pump. All infusions lasted 30 minutes. The

'Present address: The General Infirmary, Leeds.

'Correspondence to: John H. Wyllie, MD, FRCS, Senior Lecturer, Department of Surgery, University College Hospital Medical School, London.

Received for publication 22 July 1971. pentagastrin used was either the commercially available material (Peptavlon, ICI) or pentagastrin labelled with carbon-14 in the tryptophan residue, having a specific activity of $6 \mu \mathrm{Ci} / \mathrm{mg}$.

In 10 dogs cannulae were inserted into the portal and hepatic veins to sample blood entering and leaving the liver. The portal vein cannula was inserted via a splenic tributary, the spleen having been removed. The left anterior hepatic vein was cannulated by a non-occlusive technique described by Shoemaker, Walker, Van Itallie, and Moore (1959).

To take blood samples the cannulae were first filled with blood from the animal, then 3 or $10 \mathrm{ml}$ samples were simultaneously drawn from both veins at set times. The blood was placed in heparinized plastic tubes. The volume of blood so removed from the dog was immediately restored by injection of $0.15 \mathrm{M}$ sodium chloride solution and the cannulae were refilled with $0 \cdot 15 \mathrm{M}$ sodium chloride solution containing $10 \mathrm{IU} / \mathrm{ml}$ of heparin.

In eight dogs the common bile duct was cannulated for collection of bile, and the cystic duct was ligated so that bile could not collect in the gallbladder during experiments. Bile was allowed to drain by gravity, and was usually collected before, during, and for one hour after infusion of pentagastrin.

At the end of four experiments using radioactive pentagastrin the livers were removed, washed free of blood, and weighed. Samples (about $5 \mathrm{~g}$ ) were homogenized in 5 volumes of $0.25 \mathrm{M}$ sucrose using a glass Potter-Elvehjem homogenizer with a Teflon pestle. After centrifuging twice at $1,800 \mathrm{~g}$ for 10 minutes, radioactivity was measured in the supernatant.

BIOASSAY

The anaesthetized rat preparation of Smith, Lawrence, Colin-Jones, and Schild (1970) was used to measure pentagastrin in plasma and bile. Standard and test doses of pentagastrin were injected intra- 
venously into rats and the resultant production of gastric acid was measured. It was possible to assay as little as $20 \mathrm{ng}$ of pentagastrin in this way.

\section{MEASUREMENT OF RADIOACTIVITY}

The radioactivity in duplicate samples of plasma, urine, bile and supernatant from liver homogenates was measured by conventional radioactive counting procedures. From these measurements we calculated the total radioactivity excreted in urine and bile, and in the livers at the end of the experiments. The total radioactivity in the extracellular fluid was also calculated in six experiments by assuming that one hour after ending the pentagastrin infusions the pentagastrin levels in plasma were equilibrated with those in the entire extracellular water. Extracellular body water was taken to be $200 \mathrm{ml} / \mathrm{kg}$ of body weight (Spector, 1956).

\section{AUTORADIOGRAPHS}

Autoradiographs of liver were made by taking samples of liver at the end of experiments, fixing them overnight in $10 \%$ formal saline, embedding in paraffin, and cutting sections $5 \mu$ thick. These were stained with haematoxylin and eosin, and an emulsion overlay technique was used to obtain autoradiographs after 14 days' exposure at $4^{\circ} \mathrm{C}$.

\section{Results}

UNLABELLED PENTAGASTRIN IN DOGS

Pentagastrin was infused at $30 \mu \mathrm{g} / \mathrm{kg} / \mathrm{hr}$ for $30 \mathrm{~min}$ and plasma samples were obtained for analysis just before stopping the infusion, and again 10 and 20

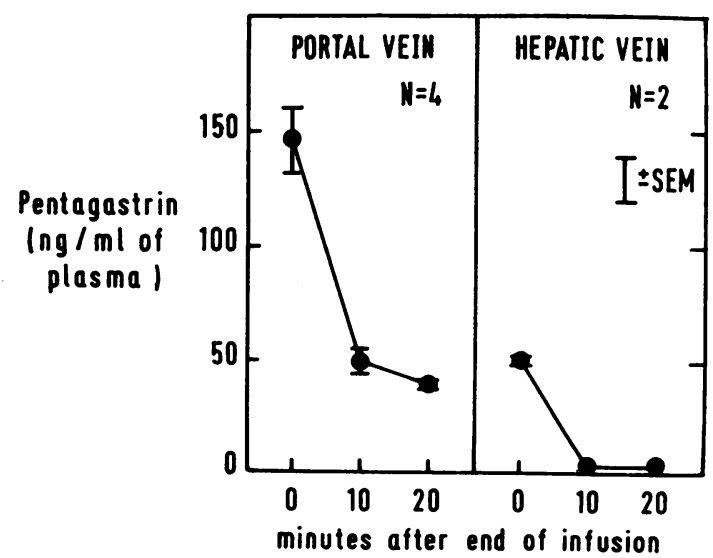

Fig. 1 Plasma levels of pentagastrin in portal and hepatic veins of dogs following intravenous infusions $(N=$ number of dogs). minutes later. As shown in Fig. 1 the infusions produced plasma levels in the dog which could easily be measured by bioassay in the rat. Portal vein levels were measured in four dogs and were compared with those in the hepatic vein in two of them. The mean value attained in the portal vein at the end of 30-min infusions $(146 \mathrm{ng} / \mathrm{ml} \pm 14 \cdot 1 \mathrm{SEM})$ was significantly higher $(\mathrm{P}<0.005)$ than that in the hepatic vein $(51.5 \mathrm{ng} / \mathrm{ml} \pm 1.5 \mathrm{SEM})$. Further assays 10 and 20 minutes after stopping the infusion failed to detect pentagastrin in the hepatic vein; the levels must therefore have been less than $10 \mathrm{ng} / \mathrm{ml}$. Rapidly declining levels were found in the portal vein. These experiments showed that pentagastrin was inactivated on passage through the liver, thus confirming our previous results (Temperley et al, 1971). They did not show what happened to the pentagastrin. It might have been metabolized to inactive derivatives which continued to circulate in the blood; it might have been taken up and stored in the liver; it might have been excreted in the bile either unchanged or as a derivative; or it might have suffered all these fates in varying proportion. To study this we carried out experiments with pentagastrin labelled with carbon-14.

\section{LABELLED PENTAGASTRIN IN DOGS}

In experiments on five dogs (experiments 4-8 of Table I) ${ }^{14} \mathrm{C}$-labelled pentagastrin was infused for $30 \mathrm{~min}$ at $30 \mu \mathrm{g} / \mathrm{kg} / \mathrm{hr}$ and blood samples were taken from portal and hepatic veins at intervals. The results were calculated in terms of disintegrations per minute per millilitre of plasma since it was recognized that pentagastrin might be broken down in the body and that some of the label might represent metabolites ahd not the infused material. Comparison of radioactivity in plasma and in successive washings of erythrocytes with $0.15 \mathrm{M} \mathrm{NaCl}$ showed that little, if any, of the label entered the erythrocytes. The plasma levels therefore represented all the pentagastrin in the blood.

The experiments all showed very similar results; mean values are shown in Figure 2. Standard errors of these means are shown, for clarity, only for selected values. Five minutes after starting an infusion radioactivity could be detected in both blood vessels: that in the portal vein always greatly exceeded that in the hepatic vein during the infusion. By 30 min the pentagastrin levels had almost ceased to rise, indicating that a steady state was being reached and that infusion of the labelled compound was approximately matched by its removal from the circulation. A t test on paired values attained at the end of the infusions ( 25 and $30 \mathrm{~min}$ ) indicated a significant difference between hepatic and portal vein levels ( $P<0.02$ in each case). The hepatic vein 


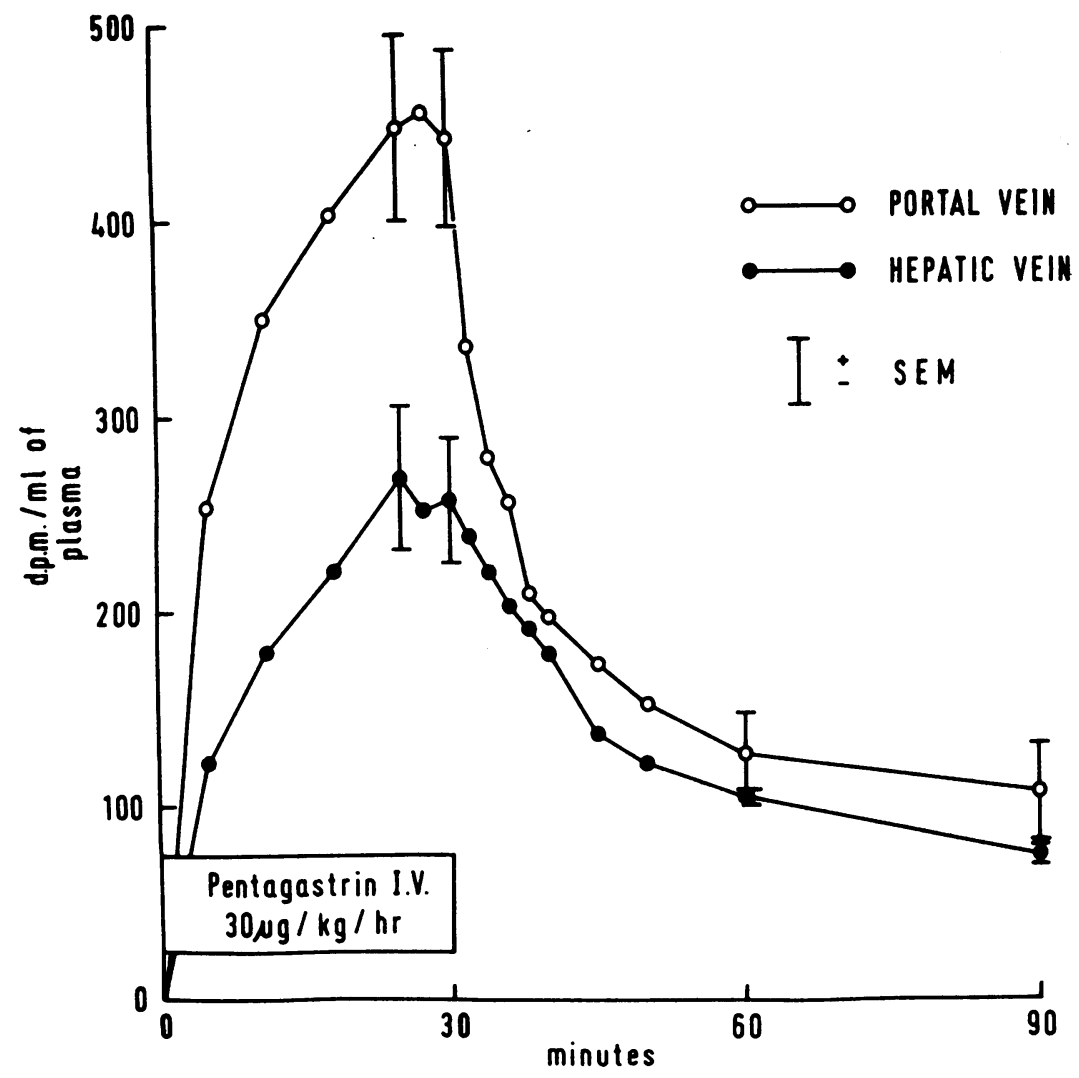

Fig. 2 Mean radioactivity in the portal and hepatic veins of five dogs during and following infusion of radioactive pentagastrin.

level averaged $61.4 \%$ of that in the portal vein, confirming the results of bioassay, and showing that the compound was actually removed from the circulation by the liver-either it was taken up and stored, or it was excreted.

On stopping the infusions the level of radioactivity fell and soon reached similar levels in the two vessels. Half and one hour after stopping the infusions $t$ tests on paired values showed that the hepatic vein levels were no longer significantly different from those in the portal vein. This result differed from that found by bioassay in which pentagastrin became undetectable in the hepatic vein. From this we inferred that the recirculating ${ }^{14} \mathrm{C}$-label was no longer attached to biologically active pentagastrin.

Assuming that one hour after the end of an infusion the radioactivity circulating in the plasma was distributed through the entire extracellular water we calculated for six experiments the percentage of the administered dose which remained in the dogs. Table I shows that the results lay between 20 and $33 \%$ (mean $24.4 \%$ ). The bulk of the radioisotope was found in the bile. This amounted to $28-80 \%$ (mean $47.0 \%$ ) of the total dose administered. A

\begin{tabular}{|c|c|c|c|c|c|c|}
\hline \multirow[t]{2}{*}{ Dog } & \multirow{2}{*}{$\begin{array}{l}\text { Dose of } \\
\text { 1"C-pentagastrin } \\
(\mu g \mid k g / h r)\end{array}$} & \multirow{2}{*}{$\begin{array}{l}\text { Biological } \\
\text { Activity } \\
\text { in Bile }\end{array}$} & \multicolumn{4}{|c|}{ Radioactivity in } \\
\hline & & & Bile & Urine & Liver & $\begin{array}{l}\text { Extra- } \\
\text { cellular } \\
\text { Fluid }\end{array}$ \\
\hline $\begin{array}{l}1 \\
2 \\
3 \\
4 \\
5 \\
6 \\
7 \\
8\end{array}$ & $\begin{array}{l}15 \\
30 \\
30 \\
30 \\
30 \\
30 \\
30 \\
30\end{array}$ & $\begin{array}{c}4 \cdot 1 \\
\overline{-}^{2} \cdot 5 \\
17 \cdot 2 \\
\overline{16 \cdot 0} \\
18 \cdot 0 \\
9 \cdot 2\end{array}$ & $\begin{array}{l}40.4 \\
80.0 \\
64.8 \\
43.5 \\
28 \cdot 1 \\
58 \cdot 1 \\
29.4 \\
32.0\end{array}$ & $\begin{array}{l}17.4 \\
- \\
- \\
11.7 \\
0.3 \\
2.4 \\
1.9 \\
4.6\end{array}$ & $\begin{array}{l}20.7 \\
- \\
- \\
- \\
24 \cdot 6 \\
16.0 \\
20.1\end{array}$ & $\begin{array}{l}26.6 \\
- \\
\overline{21} \cdot 2 \\
32 \cdot 5 \\
20 \cdot 8 \\
25 \cdot 7 \\
19 \cdot 8\end{array}$ \\
\hline
\end{tabular}

Table I Recovery of infused pentagastrin ${ }^{1}$

1The values are percentages of the total infused dose for each dog. - indicates that no measurement was made.

further considerable amount of isotope (mean $20.3 \%$ ) was recovered from the livers at the end of experiments. This represented isotope which had been excreted in the bile canaliculi and did not indicate storage of the labelled material in the liver. This was proved by making autoradiographs of liver in three experiments. Figure 3 shows the result in experiment 7 of Table I; although a few liver cells 


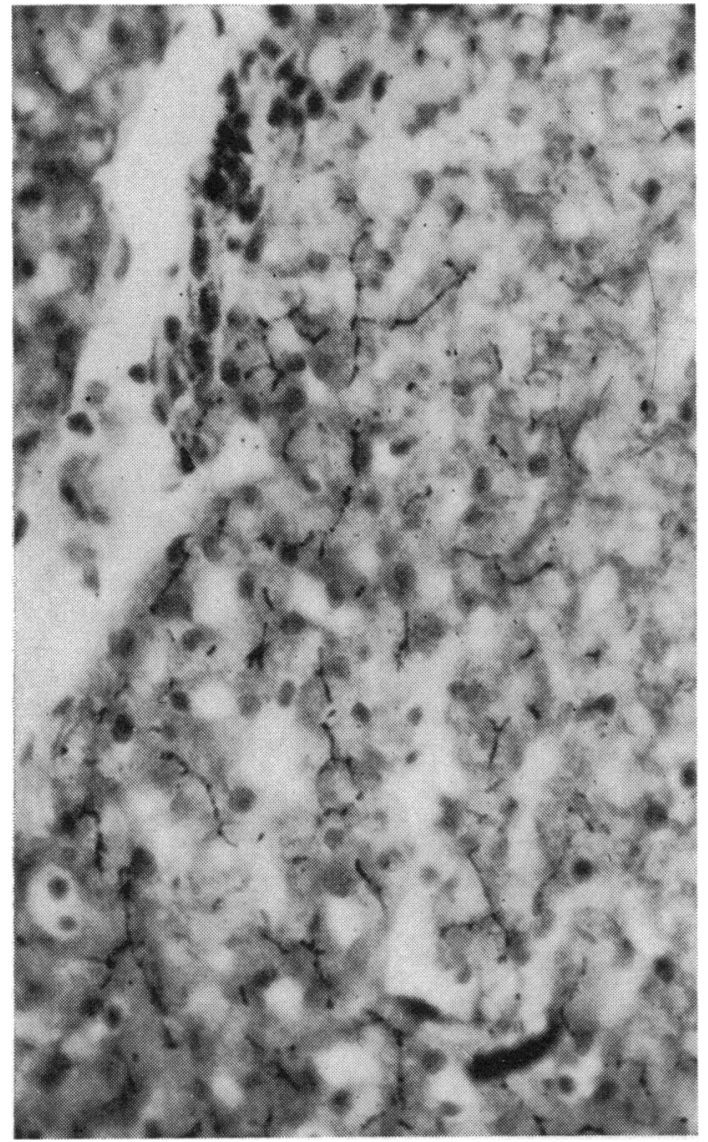

Fig. 3 Autoradiograph of dog liver one hour after infusion of radioactive pentagastrin. Although a few cells are labelled (top left), the bulk of the label is in the bile canaliculi.

contained label most of the isotope was found in the bile canaliculi. Thus hepatic excretion of the ${ }^{14} \mathrm{C}$ label accounted for about $60 \%$ of the administered isotope.

Urinary excretion was also measured in six experiments, and represented only a small percentage of the total dose. Bioassay of labelled pentagastrin was carried out on bile from six dogs, using the anaesthetized rat preparation (Smith et al, 1970). Table I shows that biological activity was detected in all six cases but the activity was lower than would be expected from the radioactivity measurements; bioactivity averaged $16 \%$ of the administered pentagastrin as compared with $45 \%$ for radioactivity. This difference was not an artefact, since (1) ${ }^{14} \mathrm{C}$ labelled and unlabelled pentagastrin had very similar potencies when assayed in the anaesthetized rat, and (2) pentagastrin added to dog bile and injected into rats gave the predicted response. It was concluded that pentagastrin was excreted either as a derivative of lower biological potency or as a mixture of an inactive derivative and unchanged pentagastrin.

\section{EXPERIMENTS IN MAN}

It is likely that pentagastrin meets a similar fate in man. We have not, of course, infused pentagastrin in man at $30 \mu \mathrm{g} / \mathrm{kg} / \mathrm{hr}$, nor have we given to man pentagastrin labelled with carbon-14. Two patients volunteered to have unlabelled pentagastrin (Peptavlon, ICI; $6 \mu \mathrm{g} / \mathrm{kg}$ subcutaneously) with their premedication. Both had been shown to have functioning gallbladders containing stones, and subsequently underwent cholecystectomy. The bile in their gallbladders was injected into rats and caused gastric secretion while bile from similar patients who had not received pentagastrin showed no such activity.

\section{Discussion}

The experiments with unlabelled pentagastrin showed that pentagastrin was inactivated by the dog liver in vivo; those with the labelled compound proved that this inactivation was the result of both excretion and metabolism of the drug. These experiments might be criticized because they employed a high rate of administration of pentagastrin: $30 \mu \mathrm{g} /$ $\mathrm{kg} / \mathrm{hr}$ is five times the dose which has usually been given to man by continuous infusion. We do not think that the fate of the drug would be different at lower dose rates because the single experiment we made using a dose rate of $15 \mu \mathrm{g} / \mathrm{kg} / \mathrm{hr}$ yielded a result quite similar to those of the other seven experiments.

In the experiments for which we have complete data (Table I) it was possible to account for 73 to $106 \%$ of the administered isotope by considering radioactivity excreted in bile and urine during the experiment and that remaining in the liver and extracellular fluid at the end. This indicates that the liver is the major site of pentagastrin metabolism in the dog.

While there is no proof that pentagastrin is similarly handled by human beings and by dogs, the limited data available from man suggest that this is so. Gastric secretagogue activity could only be detected in human bile by the injection of $0.5 \mathrm{ml}$ into the rat assay preparation. This large volume had toxic effects on the rats, so the responses could not be quantitated. It was, however, qualitatively shown that biologically active pentagastrin was excreted by the human liver following a subcutaneous injection 
of the drug. This suggests that the fate of pentagastrin in man is similar to that in the dog.

Our results are of particular interest in relation to the fate of the natural hormone gastrin. Gastrin and pentagastrin have similar actions in the body, but they meet different fates. Pentagastrin, as we have shown, is eliminated by the liver but there is no evidence of selective inactivation of gastrin by this organ. Indeed, gastrin appears to be inactivated by the kidneys (Clendinnen et al, 1970) and the gut (Temperley et al, 1971). This marked dissimilarity in the fate of the two compounds must be considered in relation to the relative potency of gastrin and pentagastrin in stimulating gastric acid secretion. The relative efficiencies of the inactivation mechanisms must at least partly determine the apparent potency ratio.

The biological activity of gastrin and pentagastrin resides in the $\mathrm{C}$-terminal tetrapeptide sequence which occurs in both molecules (Morley, Tracy, and Gregory, 1965). The rest of the gastrin molecule (residues 1-13) has not had any function attributed to it. Our results show that it is not redundant: in some way it protects the active tetrapeptide (residues 14-17) from excretion and metabolism by the liver. Perhaps the complete gastrin molecule (molecular weight 2100 ) is too large to enter hepatocytes. What- ever the explanation of the differing fates of gastrin and pentagastrin it is clear that one must not assume that the two compounds are treated similarly in the body.

We are indebted to Professors C. G. Clark and K. R. Rees for facilities and advice, Miss Lesley A. Gruby for technical assistance, and Dr J. S. Morley, ICI Ltd, for a gift of radioactive pentagastrin. Dr A. Taghizadeh kindly prepared the autoradiographs. This work was supported by grants from the Medical Research Council and the Wellcome Foundation.

\section{References}

Clendinnen, B. G., Davidson, W. D., Lemmi, C. A. E., Jackson, B. M., and Thompson, J. C. (1970). Renal uptake and excretion of gastrin in the dog. (Abstr.) Gastroenterology, 58, 935.

Morley, J. S., Tracy, H. J., and Gregory, R. A. (1965). Structurefunction relationships in the active C-terminal tetrapeptide sequence of gastrin. Nature (Lond.), 207, 1356-1359.

Shoemaker, W. C., Walker, W. F., Van Itallie, T. B., and Moore, F. D. (1959). A method for simultaneous catheterization of major hepatic vessels in a chronic canine preparation. Amer. J. Physiol., 196, 311-314.

Smith, G. M., Lawrence, A. J., Colin-Jones, D. G., and Schild, H. O. (1970). The assay of gastrin using the perfused rat stomach. Brit. J. Pharmacol., 38, 206-213.

Spector, W. S. (Ed.) (1956). Handbook of Biological Data, p. 340. Saunders, Philadelphia and London.

Temperley, J. M., Stagg, B. H., and Wyllie, J. H. (1971). Disappearance of gastrin and pentagastrin in the portal circulation. Gut, 12, 3723-76. 